\title{
FEIRANTE EMPREENDEDOR: MEIO AMBIENTE EQUILIBRADO NO USO DO ESPAÇO PÚBLICO
}

BRITO, S.S.C. ${ }^{1}$, FERREIRA, K. S. ${ }^{2}$, CAVALCANTE, L.C. ${ }^{3} \&$ PALHANO, A.C.S. ${ }^{4}$

'Estudante de Ciências Contábeis da Universidade Federal do Ceará. E-mail: saamofir@ gmail.com; ${ }^{2}$ Professora Adjunta da Universidade Federal do Ceará vinculada ao Departamento de Administração da FEAAC. Doutora em Educação Brasileira pela Universidade Federal do Ceará (2013). Mestre em Direito Público (Ordem Jurídica Constitucional) pela Universidade Federal do Ceará (2004). Graduada em Direito pela Universidade Federal do Ceará (2000) E-mail: kilviasou @gmail.com. ${ }^{3}$ Professora da Faculdade de Economia, Administração, Atuária, Contabilidade e Secretariado Executivo,Universidade Federal do Ceará, vinculada ao Departamento de Ciências Contábeis. Doutora em Sociologia pela Universidade Federal do Ceará (2012). Mestre em Direito Constitucional e Teoria do Estado pela Universidade de Fortaleza (2007). Graduada em Direito pela Universidade de Fortaleza (2000). E-mail: laracapelo@ @otmail.com. ${ }^{4}$ Estudante de Ciências Contábeis da Universidade Federal do Ceará. E-mail: carol_palhano@yahoo.com.br

DOI: https://doi.org/10.32356/exta.v2.n18.33572 - Artigo submetido em 02/09/2018

\section{RESUMO}

As feiras móveis são centros varejistas que se instauram em diferentes bairros da cidade a cada dia da semana, nesses espaços de trabalho, apesar de muitas vezes preponderar o trabalho informal, os feirantes têm direito a um meio ambiente ecologicamente equilibrado para alcançar a sadia qualidade de vida, como disposto no art. 225 da Constituição Federal do Brasil de 1988. Objetiva-se fazer um estudo sobre o comércio de rua desenvolvido na feira que ocorre no Bairro Praia do Futuro em Fortaleza, buscando compreender em que medida se dá a efetivação do direito fundamental ao meio ambiente do trabalho neste espaço público. Utilizou-se a pesquisa bibliográfica sobre meio ambiente e uso do espaço público, com as técnicas de observação participante e entrevista, apresentando a percepção dos feirantes quanto ao seu ambiente. Possibilitou-se maior disseminação acerca do meio ambiente em suas diferentes formas, notadamente no uso do espaço público que está diretamente ligado à dignidade das pessoas que exercem suas atividades no local, que dividem muito mais do que apenas um espaço físico, mais sim, um ambiente onde compartilham experiências, conhecimentos, culturas etc.

PALAVRAS-CHAVE: Feiras móveis. Meio Ambiente. Espaço Público. Trabalho.

\section{ENTREPRENEUR FAIRANT: ENVIRONMENT AND BALANCED IN THE USE OF PUBLIC SPACE}

\begin{abstract}
Mobile fairs are retail centers that retrofit the different neighborhoods of the city every day of the week, there are work spaces, even if informal work is predominant, marketers have the right to a balanced environment to achieve a healthy quality of life, as provided in art. 225 of the Federal Constitution of Brazil of 1988. The objective is to study the future of the street developed at the fair that takes place in the Praia do Futuro neighborhood in Fortaleza, seeking what is the effective integration of the law in the work environment in this public space. A bibliographic
\end{abstract}

research on environment and use of public space is used, with participant observation and interview techniques, presenting a perception of the forums for their environment. Greater dissemination about the environment was made possible in its different forms, notably in the use of public space that is directly linked to the dignity of the people who exercise their activities in the place, who share much more than just a physical space, but rather, a environment where they share experiences, knowledge, cultures etc.

KEYWORDS: Mobile Fairs. Environment. Public space. Job.

\section{INTRODUÇÃO}

As feiras são centros varejistas que se instauram em diferentes bairros da cidade a cada dia da semana, locais onde são expostos à venda diversos tipos de mercadorias, como roupas, 
alimentos e calçados. Com a incidência do capitalismo, suas novas formas de gestão e organização do trabalho e a busca por pessoas cada vez mais qualificadas, tornou as feiras uma alternativa para quem não se encaixasse nos moldes desse sistema, predominando a informalidade nesses espaços de trabalho. No Ceará, segundo documentos históricos, as feiras datam da segunda metade do século XIX (CARVALHO, 2003, p. 119) e ainda hoje permanecem ocorrendo em várias cidades do Estado. Em Fortaleza, por exemplo, encontra-se diversas feiras que ocorrem em diferentes bairros da cidade, fazendo uso do espaço público.

Nesses espaços de trabalho, apesar de muitas vezes preponderar o trabalho informal, esses feirantes são seres humanos que têm direito a um meio ambiente ecologicamente equilibrado para alcançar a sadia qualidade de vida. Esse Direito Fundamental recebe sua tutela no art. 225 da Constituição Federal de 1988 (BRASIL, 1988). Dessa forma, torna-se importante uma pesquisa que se proponha a verificaras condições de salubridade em que os feirantes exercem suas atividades laborais, analisando o que nossa Carta Magna traz como condições mínimas para uma vida digna e se essa se faz presente nas feiras, estabelecendo quais as principais reivindicações de melhorias dos mesmos, se a falta dessas melhorias fere o princípio fundamental ao meio ambiente equilibrado, bem como os princípios fundamentais da dignidade da pessoa humana, disposto no art. 1, inciso III da Constituição Federal de 1988, levantando questões sobre os impactos positivos que estas reivindicações trariam na vida dos comerciantes, caso fossem atendidas.

Esta pesquisa é oriunda de um projeto de extensão, vinculado ao Departamento de Contabilidade da Universidade Federal do Ceará, intitulado "FEIRANTE EMPREENDEDOR: Tecnologia da Informação, Desenvolvimento Humano e Crescimento Econômico no Comércio de Rua" e tem como objetivo geral fazer um estudo sobre o comércio de rua desenvolvido na feira que ocorre no bairro Praia do Futuro em Fortaleza, buscando compreender em que medida se dá a efetivação do direito fundamental ao meio ambiente do trabalho neste espaço público da cidade.

Elencam-se os seguintes objetivos específicos: a) Apresentar a definição legal de meio ambiente como um direito fundamental de terceira geração previsto na Constituição Federal de 1988, bem como apresentar as classificações doutrinárias de meio ambiente (natural, artificial, cultural e do trabalho); b) Expor os procedimentos de permissão e uso, conforme previsto no direito administrativo, evidenciando sua aplicabilidade na feira do bairro Praia do Futuro em Fortaleza; c) Entrevistar os feirantes através de visitas semanais buscando estipular o grau de 
conhecimento dos mesmos acerca de seus direitos, averiguando se estes vêm sendo efetivados e expor os dados coletados; d) Averiguar em que medida os feirantes têm interesse no desenvolvimento de um aplicativo que possa informar-lhes acerca dos seus direitos ao meio ambiente do trabalho e a regulamentação do uso do espaço público. Portanto esta pesquisa pretende responder a seguinte pergunta: Em que medida o direito fundamental ao meio ambiente do trabalho tem se efetivado no desenvolvimento da atividade laboral dos comerciantes que fazem uso do espaço público da feira do bairro Praia do Futuro em Fortaleza?

Foram adotados os seguintes procedimentos metodológicos: Pesquisa bibliográfica, que para LAKATOS e MARCONI (2007, p. 72) tem a finalidade de "colocar o pesquisador em contato direto com tudo o que foi escrito, dito ou filmado sobre determinado assunto"; visitas semanais à feira que ocorre aos sábados no bairro Praia do Futuro em Fortaleza, sendo utilizadas duas técnicas de pesquisa para isso. A primeira é a observação participante, que consiste no contato direto e integração do observador com o grupo em estudo, examinando as condições em que vivem e vivenciando um pouco desta realidade. A segunda técnica é a entrevista, que é um encontro entre duas partes, entrevistador e entrevistado, em que o primeiro busca obter informações sobre o assunto ou problema em questão, através de uma conversação, sendo não estruturado o tipo de entrevista utilizado e sua modalidade focalizada, na qual o entrevistador tem liberdade para desenvolver perguntas e diálogos de acordo com a situação e necessidade.

\section{CONCEITO E CLASSIFICAÇÃO DOS DIREITOS FUNDAMENTAIS}

A Constituição Federal de 1988 em seu Título II, trouxe os direitos e garantias fundamentais, classificando nos seguintes grupos: direitos individuais e coletivos; direitos sociais; nacionalidade; direitos políticos e partidos políticos. Dessa classificação, a doutrina apresenta a classificação dos direitos fundamentais de primeira, segunda, terceira, quarta e quinta geração ou dimensão.

Para Araújo e Nunes Júnior (2005, p. 109-110.)

Os direitos fundamentais podem ser conceituados como a categoria jurídica instituída com a finalidade de proteger a dignidade humana em todas as dimensões. Por isso, tal qual o ser humano, tem natureza polifacética, buscando resguardar o homem na sua liberdade (direitos individuais), nas suas necessidades (direitos sociais, econômicos e culturais) e na sua preservação (direitos relacionados à fraternidade e à solidariedade).

Como explica Morais (2008, p. 31) os direitos fundamentais de primeira geração ou dimensão "são os direitos e garantias individuais e políticos clássicos (liberdades públicas), surgidos institucionalmente a partir da Magna Charta.”. Segundo Bonavides (2013, p. 582): 
Os direitos de primeira geração ou direitos de liberdades têm por titular o indivíduo, são oponíveis ao Estado, traduzem-se como faculdades ou atributos da pessoa e ostentam uma subjetividade que é seu traço mais característico; enfim, são direitos de resistência ou de oposição perante o Estado.

Os direitos de segunda dimensão são os direitos sociais, econômicos e culturais, que surgiram no início do século XX, como bem coloca Themistocles Brandão Cavalcanti:

\begin{abstract}
O começo do nosso século viu a inclusão de uma nova categoria de direitos nas declarações e, ainda mais recentemente, nos princípios garantidores da liberdade das nações e das normas da convivência internacional. Entre os direitos chamados sociais, incluem-se aqueles relacionados com o trabalho, o seguro social, a subsistência, o ampara à doença, à velhice etc.”. (CAVALCANTI apud MORAIS, 2008, p. 31)
\end{abstract}

Os direitos de terceira dimensão, como explica Pedro Lenza (2011, p. 862) "são direitos transindividuais que transcendem os interesses do indivíduo e passam a se preocupar com a proteção do gênero humano, com altíssimo teor de humanismo e universalidade". São protegidos constitucionalmente e chamados de direitos de solidariedade ou fraternidade, que é o caso do direito a um meio ambiente equilibrado, um dos objetos de estudo deste trabalho. Para Ferreira Filho (2007) ao tratar do direito ao meio ambiente como de terceira geração, sustentou que, dentre os direitos da terceira geração, o mais elaborado é o direito ao meio ambiente ecologicamente equilibrado, pois é um direito assegurado à pessoa humana e é garantido pelo Poder Público como fundamental. Estabelecendo um superdireito que se sobrepõe aos direitos de natureza privada.

Para Bonavides (2013), a introdução aos direitos da quarta geração se dá por meio da globalização política na esfera da normatividade jurídica, que correspondem à derradeira fase de institucionalização do Estado social. Compreendem os direitos da quarta geração, segundo o autor:

O direito à democracia, o direito à informação e o direito ao pluralismo. Deles depende a concretização da sociedade aberta do futuro, em sua dimensão de máxima universalidade, para a qual parece o mundo inclinar-se no plano de todas as relações de convivência. (BONAVIDES, 2013, p. 590)

Portanto, para Bonavides (2013, p. 591), da globalização dos direitos fundamentais decorrem os direitos da $4^{\mathrm{a}}$ dimensão e conclui que "os direitos da quarta geração compreendiam o futuro da cidadania e o porvir da liberdade de todos os povos. Tão somente com eles será legítima e possível a globalização política."

Por fim, na quinta geração de direitos fundamentais, elencada por Bonavides, está o direito à paz, inicialmente posto por Karel Vasak, o precursor da terceira geração de direitos 
fundamentais. Bonavides afirma que a paz é axioma da democracia participativa, um supremo direito da humanidade.

\subsection{MEIO AMBIENTE COMO DIREITO FUNDAMENTAL: ART. 225 DA CF/88}

$\mathrm{O}$ direito fundamental ao meio ambiente ecologicamente equilibrado, erigido pela Constituição Federal de 1988 , em seu art. $255^{\circ}$, é tratado como um bem de uso comum do povo e essencial à sadia qualidade de vida, que deve ser protegido pelo Estado e pela coletividade, não se limitando apenas a um dos aspectos de Meio Ambiente, dando a ideia deste como uma relação entre seres vivos e seu meio.

\subsubsection{DEFINIÇÃO LEGAL, CLASSIFICAÇÃO E PROTEÇÃO CONSTITUCIONAL DO MEIO AMBIENTE}

O conceito legal de Meio Ambiente, de acordo com a Lei da Política Nacional de Meio Ambiente - Lei 6.938/81 - em seu artigo 3º , I, é: “conjunto de bens, influências e interações de ordem físicas, químicas e biológicas, que permite, abriga e rege a vida em todas as suas formas" (BRASIL, 1981). Essa concepção legal diz respeito ao Meio Ambiente Natural, sendo este um dos quatro aspectos de Meio Ambiente, quais sejam: o já citado natural, o artificial, o cultural e o do trabalho. Essa classificação tem a função de facilitar a identificação de atividades degradantes e do bem agredido, não buscando estabelecer divisões isolantes a este, visto que seu objetivo maior de tutelar a vida saudável faz-se necessário proteger o ambiente em sua totalidade (FIORILLO, 2002). O presente trabalho dará enfoque ao Meio Ambiente do trabalho e artificial.

O meio ambiente do trabalho, nasce do entendimento que o homem faz parte do meio ambiente ecologicamente equilibrado, haja visto que é essencial à sobrevivência do mesmo, por ser seu habitat natural e local no qual obtém recursos para a manutenção da sua vida com sua atividade laboral e onde passa grande parte de sua vida, de modo que não é possível alcançar qualidade de vida sem ter qualidade de trabalho, fez-se necessário proteger este ambiente, que recebe tutela constitucional imediata no artigo 200, VIII e a mediata no caput do art. 225.

Com isso, precisamos buscar uma definição para meio ambiente de trabalho e, portanto, trazemos o pensamento de Júlio César de Sá da Rocha, para quem:

É possível conceituar o meio ambiente do trabalho como a ambiência na qual se desenvolvem as atividades do trabalho humano. Não se limita ao empregado; todo 
trabalhador que cede a sua mão-de-obra exerce sua atividade em um ambiente de trabalho. Diante das modificações que passa o trabalho, o meio ambiente laboral não se restringe ao espaço interno da fábrica ou da empresa, mas se estende ao próprio local de moradia ou ao ambiente urbano. (SÁ apud PADILHA,2002, p. 41)

Por sua vez, Rodolfo de Camargo Mancuso aponta o meio ambiente do trabalho como:

Habitat laboral, isto é, tudo que envolve e condiciona, direta e indiretamente, o local onde o homem obtém os meios para prover o quanto necessário para a sua sobrevivência e desenvolvimento, em equilíbrio com o ecossistema. (CANCUSO apud PADILHA, 2002, p.41)

Assim, quando no habitat laboral não houver o mínimo de condições para assegurar certa qualidade de vida, haverá um dano ao meio ambiente do trabalho, como o é o caso da saúde e segurança no trabalho, que também recebem proteção constitucional em seu art. $7^{\circ}$ :

Art. $7^{\circ}$ São direitos dos trabalhadores urbanos e rurais, além de outros que visem à melhoria de sua condição social:

(...)

XXII - redução dos riscos inerentes ao trabalho, por meio de normas de saúde, higiene e segurança;

O conceito de meio ambiente cultural está previsto no, que o traz da seguinte forma:

Art. 216. Constituem patrimônio cultural brasileiro os bens de natureza material e imaterial, tomados individualmente ou em conjunto, portadores de referência à identidade, à ação, à memória dos diferentes grupos formadores da sociedade brasileira, nos quais se incluem:

I - as formas de expressão;

II -os modos de criar, fazer e viver;

III - as criações científicas, artísticas e tecnológicas;

IV - as obras, objetos, documentos, edificações e demais espaços destinados às manifestações artístico-culturais;

V - os conjuntos urbanos e sítios de valor histórico, paisagístico, artístico, arqueológico, paleontológico, ecológico e científico.

Assim, para Fiorillo (2002, p. 22):

O bem que compõe o chamado patrimônio cultural traduz a história de um povo, a sua formação, cultura e, portanto, os próprios elementos identificadores de sua cidadania, que constitui princípio fundamental norteador da República Federativa do Brasil.

Já o meio ambiente artificial é compreendido pelo espaço urbano construído, consubstanciado no conjunto de edificações e equipamentos públicos, este recebe tutela mediata no caput do art. 225 e imediata no art. 182, referente à política urbana, no art $5^{\circ}$, XXIII e 21, XX, estando diretamente relacionado ao conceito de cidade. Assim dispõe o art. 182 da $\mathrm{CF}$, iniciando o capítulo referente à política urbana: "art. 182. A política de desenvolvimento urbano, executada pelo Poder Público municipal, conforme diretrizes gerais fixadas em lei, tem 
por objetivo ordenar o pleno desenvolvimento das funções sociais da cidade e garantir o bemestar de seus habitantes". Logo, um dos princípios da política urbana é o pleno desenvolvimento das funções sociais da cidade, que para FIORILLO (2002, p. 206)

A função social da cidade é cumprida quando esta proporciona a seus habitantes o direito à vida, à segurança, à igualdade, à propriedade e à liberdade $\left(\mathrm{CF}\right.$, art. $5^{\circ}$, caput $)$, bem como quando garante a todos um piso mínimo, compreendido pelos direitos sociais à educação, à saúde, ao lazer, ao trabalho, à previdência social, à maternidade, à infância, à assistência aos desamparados, entres outros encartados no art. $6^{\circ}$.

Assim esclarece o autor: "Em linhas gerais, a função social da cidade é cumprida quando proporciona a seus habitantes uma vida com qualidade, satisfazendo os direitos fundamentais, em consonância com o que o art. 225 preceitua."

Por fim, conclui o autor supracitado, que cabe a cidade viabilizar o desenvolvimento das atividades laborativas, para gerar possibilidades reais de trabalho aos seus habitantes.

\subsection{PERMISSÃO DE USO DO ESPAÇO PÚBLICO E SUA APLICABILIDADE NA FEIRA DO BAIRRO DA PRAIA DO FUTURO}

Os bens públicos podem ser usados tanto pela pessoa jurídica a que pertencem quanto por particulares. O uso do espaço público se dá por ato ou contrato administrativo. Segundo Carvalho Filho (2010, p. 109) ato administrativo é "a exteriorização da vontade de agentes da Administração Pública ou de seus delegatários, nessa condição, que, sob regime de direito público, vise à produção de efeitos jurídicos, com o fim de atender ao interesse público”. Ainda, segundo Alexandrino e Paulo (2011, p. 416) ato administrativo é:

\footnotetext{
Manifestação ou declaração da administração pública, nesta qualidade, ou de particulares no exercício de prerrogativas públicas, que tenha por fim imediato a produção de efeitos jurídicos determinados, em conformidade com o interesse público e sob regime predominante de direito público.
}

No caso do contrato, os autores supracitados trazem o seguinte conceito "ajuste firmado pela administração pública, agindo nesta qualidade, com particulares, ou com outras entidades administrativas, nos termos estipulados pela própria administração pública contratante, em conformidade com o interesse público, sob regência predominante do direito público".

No caso da feira que ocorre no bairro Praia do Futuro, a forma de obtenção da permissão do uso do espaço público é, de fato, um ato permissionário, conforme explicado em uma visita realizada à Secretaria Regional II a fim de descobrir os passos para obtenção da permissão de uso do espaço público, são descritos da seguinte forma: 1) dar entrada em processo 
administrativo, sendo necessário documentação completa (Registro Geral - RG; cadastro de pessoa física - CPF; comprovante de residência e número de identificação social - NIS, caso faça parte de algum programa de ajuda social ou possua baixa renda); 2) o processo será encaminhado ao setor jurídico do órgão, posteriormente levado ao gabinete do secretário, seguindo para a célula de gestão de ações intersetoriais; 3) será elaborado parecer junto a um fiscal da Agência Nacional de Fortaleza (AGEFIS); 4) No caso de haver despacho do fiscal, deve ser encaminhado à Coordenadoria de Acolhimento Social; 5) Por fim, o secretário deve decidir sobre a obtenção da permissão de uso do espaço público pelo indivíduo.

Além disso, foi aberto um requerimento solicitando a quantidade de comerciantes que atuam na feira, bem como a quantidade que possuem a permissão da prefeitura para usufruir do espaço público, com base no princípio da transparência dos dados públicos, porém até a finalização deste artigo, não houve resposta. Contudo, em nossa contagem, registramos 105 bancas, comportando um total de 196 comerciantes distribuídos entre estas, além de 38 comerciantes que trabalham sem bancas fixas.

\section{MATERIAIS E MÉTODOS}

Inicialmente, utilizou-se a pesquisa bibliográfica em artigos, livros e na Constituição Federal de 1988. Para LAKATOS e MARCONI (2007, p. 72) a finalidade da pesquisa bibliográfica é "colocar o pesquisador em contato direto com tudo o que foi escrito, dito ou filmado sobre determinado assunto".

Para a inserção no campo, foram realizadas visitas semanais à feira que ocorre aos sábados no bairro da Praia do Futuro em Fortaleza, local onde os feirantes vendem suas mercadorias como, frutas, verduras, laticínios, roupas, dentre outros, com início no dia 19 de abril de 2018, durante 9 meses. Na coleta de dados, buscou-se analisar a visão dos feirantes sobre o seu local de trabalho, se estes consideravam o mesmo ideal para a realização de suas atividades laborais, levando em consideração quais as maiores carências e a salubridade do local. A seguir, traremos à luz alguns depoimentos dos feirantes sobre esses temas, exemplificando suas visões sobre o seu trabalho.

\subsection{PERCEPÇÃO DOS FEIRANTES ACERCA DA EFETIVAÇÃO DOS DIREITOS RELATIVOS AO MEIO AMBIENTE DO TRABALHO}


Adotando-se um processo que garantisse a aleatoriedade dos sujeitos participantes, dando a todos a mesma possibilidade de participação na pesquisa, foram realizados diálogos com 60 feirantes que aceitaram participar da pesquisa pelo critério de conveniência. Sendo assim, foi possível delimitar os aspectos mais importantes sobre a sua qualidade de vida na feira, analisando os temas que melhor atendem ao requisito meio ambiente do trabalho equilibrado e a visão dos feirantes sobre o seu meio. Primeiramente, será analisado o depoimento de 3 feirantes sobre os fatores que poderiam favorecer a sua qualidade de vida nas feiras. Logo após, serão analisadas 3 depoimentos sobre a salubridade do seu local de trabalho e nos dois casos serão expostos o interesse ou não dos feirantes a um aplicativo com informações sobre Meio ambiente.

Um primeiro informante, que atua no setor alimentício junto ao seu patrão, com um comércio de frutas e verduras, trabalhando há um ano como feirante. $\mathrm{O}$ mesmo alega pagar a limpeza e a segurança, mas diz que essa não é sua responsabilidade "a gente paga tanto imposto e não tem direitos, a responsabilidade é da prefeitura" (informação verbal), o feirante também queria um banheiro e não tem interesse no aplicativo. Já o seu patrão, de 46 anos e atuante na feira desde os 9 anos de idade, ao falar dos itens que poderiam melhorar na feira para favorecer sua qualidade de vida, cita banheiro, segurança e limpeza, apontando para uma quantidade de escombros que, segundo ele, estão a mais de 5 anos no local. Quanto ao aplicativo, ele diz ter interesse.

Um segundo relato vem um senhor de 71 anos, que trabalha com seu neto no comércio de tempero seco, atuando na feira há 52 anos, ao ser questionado, afirma que não adianta falar nada, pois não haverá mudanças, ainda afirma que em época eleitoral foram disponibilizados banheiros químicos, mas após 2 dias, foram retirados. Já o seu neto de 23 anos e atuante na feira há 5 meses, acha que não há fatores que possam melhorar sua qualidade de vida, mas tem interesse no aplicativo, já seu avô diz não ter interesse.

O terceiro informante, com 52 anos e 1 ano trabalhando na feira, com um comércio de polpa de frutas, diz que não há fatores que poderiam melhorar sua qualidade de vida, pois está satisfeito "ganhando o dinheirinho da gente" (informação verbal). O mesmo afirma que a prefeitura já colocou um banheiro, mas que tirou com poucos dias e não tem interesse no aplicativo.

Quanto à salubridade do local de trabalho, serão analisados 3 depoimentos.

O primeiro informante, de 28 anos e atuante na feira há 7 anos, que trabalha no setor 
alimentício, junto de seu sócio e tem um comércio de verduras, diz que existem riscos à saúde e que o mesmo havia acabado de se acidentar ao pegar uma caixa de tomates de mal jeito e que estava sentindo dor. Ao perguntarmos o que faziam quando alguém se acidenta na feira, ele respondeu que "quando acontece algo as pessoas da feira que levam para o hospital" (informação verbal). Seu sócio, de 25 anos e há 2 anos como feirante, relata que existem riscos, pois não tem tratamento de higiene, trabalham ao ar livre e estão sujeitos a doenças. Ele relata que em épocas de chuva, costuma passar uma quantidade enorme de água que desce do morro, próximo à feira e que já teve doenças de pele após entrar em contato com a água, além de citar o contato excessivo com o calor, decorrente da longa exposição ao sol. Ambos responderam não ter interesse no aplicativo, o segundo acredita que haveria cobranças por parte do Estado no caso da existência deste, como assim disse: “a pessoa já vem porque é feira livre, sem controle do governo. Se o governo controlar aqui as pessoas vão sair. Se fizer isso aí, o governo vai cair em cima, vai querer imposto, querem fazer tudo pra cobrar a gente." (informação verbal)

Em um segundo relato, um casal que trabalha em uma banca de vestuário afirma que em qualquer lugar existem riscos. O jovem de 21 anos ao responder a pergunta, diz que é o dia a dia deles e que isso é normal no Brasil. Sua esposa de 21 anos concorda com suas afirmações e acrescenta "a gente tem que se adaptar e se proteger" (informação verbal). Não foi possível questionar quanto ao aplicativo.

Um terceiro informante, de 48 anos, não vê riscos à saúde, porém diz que a exposição ao Sol é um problema e que utiliza duas lonas na sua banca na tentativa de diminuir o calor. Sobre o aplicativo, o feirante diz ter interesse.

\section{RESULTADO E DISCUSSÕES}

Em diálogos realizados com 60 comerciantes da feira que ocorre no bairro Praia do Futuro, foi possível analisar as condições que eles enxergam o seu ambiente de trabalho, tendo em vista a conveniência dos feirantes em responder as perguntas, da seguinte forma: a) se existem ou não fatores que poderiam melhorar a qualidade de vida dos feirantes e em caso positivo, quais são esses fatores; b) se existem riscos ou não à saúde no trabalho dos feirantes e em caso positivo, quais são esses riscos; c) se existe interesse de obter mais informações sobre meio ambiente do trabalho e ao uso do espaço público por meio de um aplicativo desenvolvido para auxiliar o feirante nas suas atividades laborais. Acerca das relações de trabalho observadas 
e desempenhadas por cada feirante, levando em conta a pesquisa e os dados coletados foi possível destacar as seguintes observações:

QUADRO 1 - Classificação dos feirantes no que diz respeito aos fatores que possam melhorar sua qualidade de vida

$\begin{array}{cccc}\text { SETOR } & \text { ACHAM QUE EXISTEM } & \text { ACHAM QUE NÃO } & \text { NÃO SE } \\ & \text { FATORES QUE PODEM } & \text { EXISTEM FATORES QUE } & \text { PRONUNCIARAM } \\ & \text { FAVORECER A } & \text { PODEM FAVORECER A } & \\ & \text { QUALIDADE DE VIDA } & \text { QUALIDADE DE VIDA } & \\ \text { DOS FEIRANTES } & \text { DOS FEIRANTES } & 2 \\ \text { VARIADOS } & 37 & 3 & 2 \\ \text { TOTAL } & 13 & 2 & 4\end{array}$

Fonte: Arquivo pessoal do autor (2018)

Dado a diversidades de ofertas de produtos na feira, além dos alimentícios que envolvem bancas com venda de frutas, verduras, peixes, laticínios e outros, existem também vendas de roupas, bijuterias, eletrônicos, utensílios etc., que foram classificados como variados.

Dentre os trabalhadores da feira que acham que existem fatores que podem favorecer sua qualidade de vida, obteve-se as seguintes informações quando questionados sobre quais seriam estes, conforme gráfico abaixo:

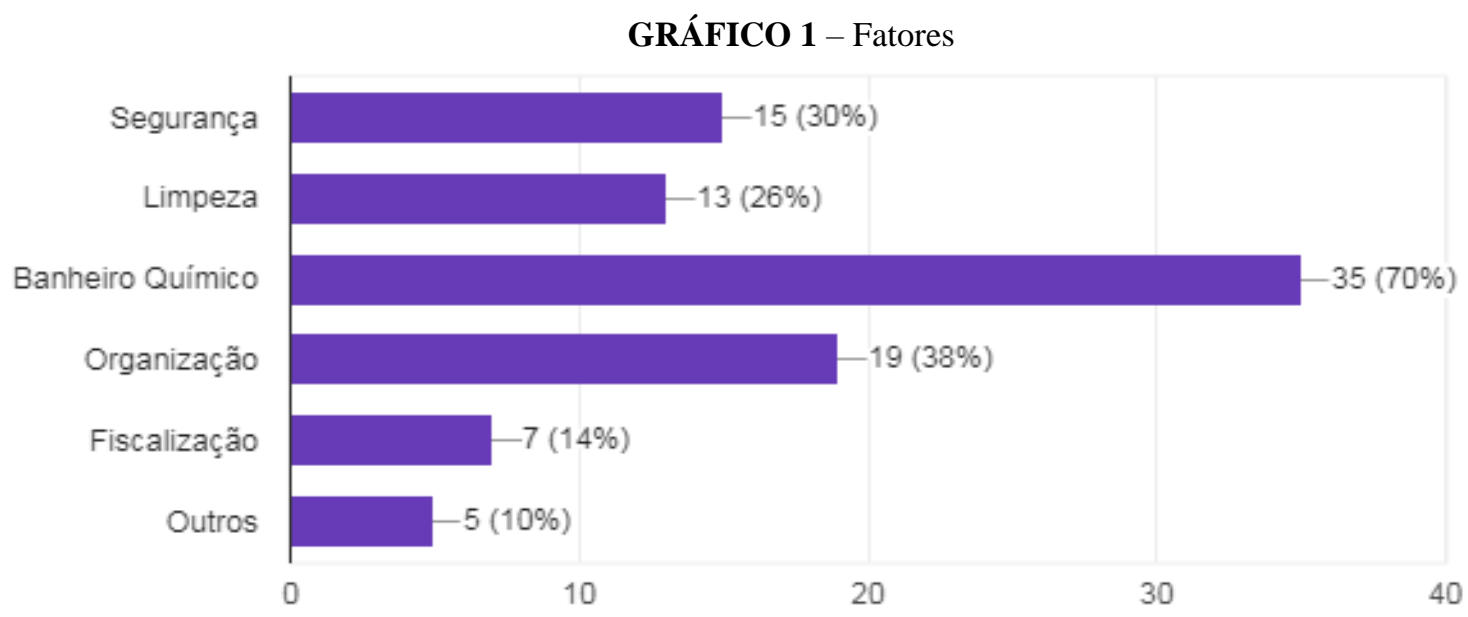

Fonte: Arquivo pessoal do autor (2018)

Quando perguntados se existem riscos ou não à saúde no trabalho dos feirantes obteve-se os seguintes resultados de acordo com a amostra pesquisada:

QUADRO 2 - Classificação dos feirantes no que diz respeito ao risco à saúde do feirante no ambiente de trabalho 


\begin{tabular}{ccc}
\hline SETOR & ACHAM QUE EXISTEM & ACHAM QUE NÃO EXISTEM \\
& RISCOS Ã SAÚDE DO & RISCO Á SAÚDE DO \\
& REIRANTE NO AMBIENTE & FEIRANTE NO AMBIENTE \\
& DE TRABALHO DA FEIRA & DE TRABALHO DA FEIRA \\
DEIMENTÍCIO & 20 & 12 \\
VARIADOS & 4 & 1 \\
TOTAL & 24 & 13 \\
\hline
\end{tabular}

Fonte: arquivo pessoal do autor (2018)

Dentre os feirantes que acham que existem riscos à saúde no seu ambiente laboral, obtevese as seguintes informações quando questionados sobre quais seriam estes, conforme gráfico abaixo:

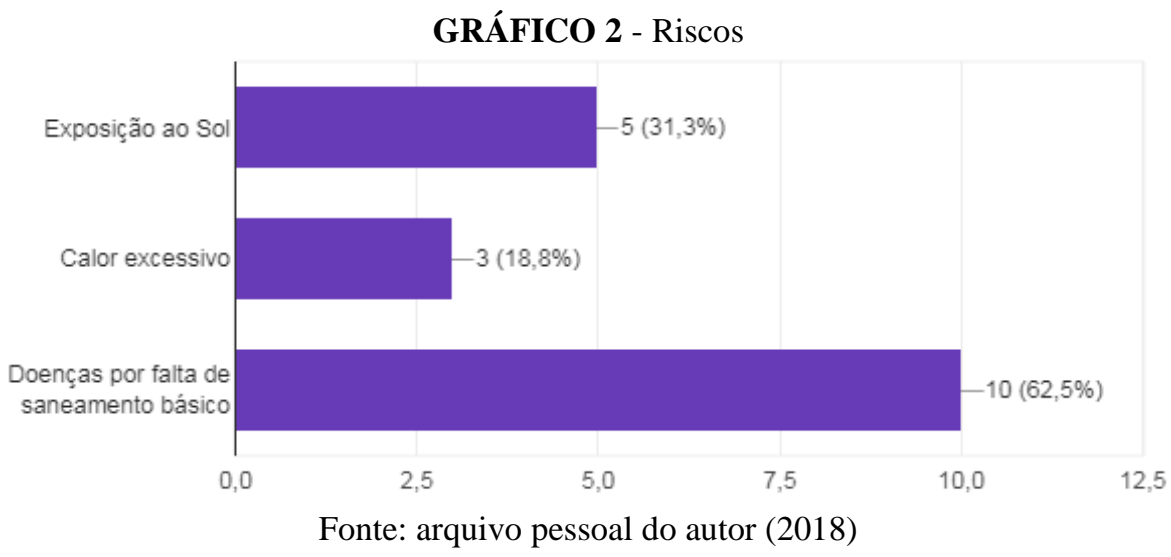

No que diz respeito ao nível de interesse de obter mais informações sobre meio ambiente do trabalho e ao uso do espaço público por meio de um aplicativo, os feirantes com faixa etária até 40 anos demonstraram maior interesse em usar essa ferramenta, conforme a tabela a seguir:

QUADRO 3 - Classificação dos feirantes no que diz respeito a obter maiores informações sobre meio ambiente de trabalho e ao uso do espaço público

IDADE

ATÉ 40 ANOS DE IDADE

MAIS DE 40 ANOS

TOTAL

\section{DESEJAM OBTER MAIS INFORMAÇÕES}

14 23

\section{NÃO POSSUEM INTERESSE}

EM OBTER MAIS

INFORMAÇÕES

24 34

Fonte: arquivo pessoal do autor (2018)

\section{CONCLUSÃO}

Analisar a visão nativa dos feirantes possibilita compreender a sua percepção sobre as condições onde exercem suas atividades laborais e o nível de efetividade do direito fundamental ao meio ambiente ecologicamente equilibrado, previsto na Constituição Federal de 1988, bem como o uso do espaço público na feira móvel e as suas necessidades perante o Estado e a sociedade em geral. Com isso, a esfera pública pode, da melhor maneira possível, realizar diversos projetos voltados às carências desse ambiente, almejando a sadia qualidade de vida 
para as pessoas que usam o espaço para sua subsistência, como as que cercam o local. Além disso, faz-se necessária atuação conjunta com a Universidade no que diz respeito à criação de projetos para disseminar o conhecimento acerca do meio ambiente em suas diferentes formas, a fim de que conhecendo a sua realidade, esses feirantes possam reivindicar os seus direitos.

Constatou-se que a necessidade de uma devida atenção a esse espaço está diretamente ligado à dignidade das pessoas que exercem suas atividades no local, que dividem muito mais do que apenas um espaço físico, mais sim, um ambiente onde compartilham experiências, conhecimentos, culturas etc. Sugere-se para as futuras investigações que a qualidade de vida desses comerciantes continue sendo estudada, com o intuito de estabelecer um panorama muito mais amplo sobre o ambiente da feira e a realidade na qual exercem suas atividades.

\section{REFERÊNCIAS}

ALEXANDRINO, Marcelo; PAULO, Vicente. Direito administrativo descomplicado. 19. ed. rev. atual.. Rio de Janeiro: Forense: São Paulo: MÉTODO. 2011.

ARAUJO, Luiz Alberto David; NUNES JÚNIOR, Vidal Serrano. Curso de Direito Constitucional. 9. ed. São Paulo: Saraiva, 2005.

BONAVIDES, Paulo. Curso de Direito constitucional. 28. ed. atual. São Paulo: Malheiros Editores. 2013.

BRASIL. LEI Nº 6.938, de 31 de agosto de 1981. Dispõe sobre a Política Nacional do Meio Ambiente, seus fins e mecanismos de formulação e aplicação, e dá outras providências. Brasília, Disponível em: <http://www.planalto.gov.br/ccivil_03/Leis/L6938.htm>. Acesso em: 10 de junho de 2018 .

BRASIL. Constituição (1988). Constituição da República Federativa do Brasil. Brasília, DF: Senado Federal, 1988.

CARVALHO, Gilmar de. Bonito pra chover: ensaios sobre a cultura cearense. Fortaleza: Edições Demócrito Rocha, 2003.

CARVALHO FILHO, José dos Santos. Manual de direito administrativo. 23 ed. rev., ampl. e atualizada até 31.12.2009. Rio de Janeiro: Lumen Juris. 2010.

FERREIRA FILHO, Manoel Gonçalves. Direitos humanos fundamentais. 9. ed. rev. São Paulo: Saraiva, 2007.

FIORILLO, Celso Antônio Pacheco. Curso de Direito Ambiental Brasileiro. 3 ed. ampl. São Paulo: Saraiva, 2002.

LAKATOS, Eva Maria; MARCONI, Marina de Andrade. Técnicas de pesquisa: 
planejamento e execução de pesquisas, amostragens e técnicas de pesquisa, elaboração e interpretação de dados.6. ed. 2. reimpr. São Paulo: Atlas, 2007.

LENZA, Pedro. Direito Constitucional Esquematizado. 15. ed. rev., atual. eampl. São Paulo: Saraiva, 2011.

MORAES, Alexandre de. Direito constitucional. 23. ed. São Paulo: Atlas, 2008.

PADILHA, Norma Sueli. Do meio ambiente do trabalho equilibrado. São Paulo: LTr, 2002. 